\title{
Production of two highly active bacterial phytases with broad pH optima in germinated transgenic rice seeds
}

\author{
Chwan-Yang Hong ${ }^{1,4}$, Kuo-Joan Cheng ${ }^{2}$, Tung-Hai Tseng ${ }^{3}$, Chang-Sheng Wang ${ }^{3}$, Li-Fei Liu ${ }^{4, *}$ \\ \& Su-May $\mathrm{Yu}^{1, *}$ \\ ${ }^{1}$ Institute of Molecular Biology, Academia Sinica, Nankang, Taipei 11529, Taiwan, ROC \\ ${ }^{2}$ Institute of BioAgricultural Sciences, Academia Sinica, Nankang, Taipei 11529, Taiwan, ROC \\ ${ }^{3}$ Taiwan Agricultural Research Institute, Wu-Fong, Taichung, Taiwan, ROC \\ ${ }^{4}$ Department of Agronomy, National Taiwan University, Taipei, Taiwan, ROC
}

Received 24 March 2003; revised 24 June 2003; accepted 16 July 2003

Key words: $\alpha$-amylase gene promoter, feed additive, germinating seeds, phytase, rice

\begin{abstract}
Phytate is the main storage form of phosphorus in many plant seeds, but phosphate bound in this form is not available to monogastric animals. Phytase, an enzyme that hydrolyzes phosphate from phytate, has the potential to enhance phosphorus availability in animal diets when engineered in rice seeds as a feed additive. Two genes, derived from a ruminal bacterium Selenomonas ruminantium (SrPf6) and Escherichia coli (appA), encoding highly active phytases were expressed in germinated transgenic rice seeds. Phytase expression was controlled by a germination inducible $\alpha$-amylase gene $(\alpha A m y 8)$ promoter, and extracellular phytase secretion directed by an $\alpha A m y 8$ signal peptide sequence. The two phytases were expressed in germinated transgenic rice seeds transiently and in a temporally controlled and tissue-specific manner. No adverse effect on plant development or seed formation was observed. Up to 0.6 and $1.4 \mathrm{U}$ of phytase activity per $\mathrm{mg}$ of total extracted cellular proteins were obtained in germinated transgenic rice seeds expressing appA and SrPf6 phytases, respectively, which represent 46-60 times of phytase activities compared to the non-transformant. The appA and $\operatorname{SrPf6}$ phytases produced in germinated transgenic rice seeds had high activity over broad $\mathrm{pH}$ ranges of 3.0-5.5 and 2.0-6.0, respectively. Phytase levels and inheritance of transgenes in one highly expressing plant were stable over four generations. Germinated transgenic rice seeds, which produce a highly active recombinant phytase and are rich in hydrolytic enzymes, nutrients and minerals, could potentially be an ideal feed additive for improving the phytate-phosphorus digestibility in monogastric animals.
\end{abstract}

\section{Introduction}

Phytate (myo-inositol hexakisphosphate) is the main storage form of phosphorus in many seeds. In cereals, legumes and Brassicae, phytate accumulates in seeds during maturation and accounts for $50-80 \%$ of total phosphorus (Austin et al., 1994). Soybean and corn meals are major components of animal feed and contain adequate phosphorus levels to meet an-

*Authors for correspondence

E-mails: sumay@ccvax.sinica.edu.tw, 1fliu@ntu.edu.tw imal growth requirements if phosphorus from phytate could be made available. However, monogastric animals (e.g., pigs, poultry and fish) utilize phytate extremely poorly due to deficiencies in gastrointestinal tract enzymes capable of hydrolyzing phytate, which necessitates supplementation of animal rations with expensive phosphorus to meet dietary requirements (Ravindran et al., 1995). When used as feed, phytatephosphorus passes through the gastrointestinal tract of monogastric animals and is excreted in the manure. Consequently, a significant amount of nutritionally important phosphorus is not utilized by the animals. The excreted phosphorus contributes significantly 
to the phosphate pollution problem in areas with intensive livestock farming.

Phosphorus availability to monogastric animals has been improved by the supplementation of animal feed with phytase (myo-inositol hexakisphosphate phosphohydrolase, EC 3.1.3.8) from the fungus Aspergillus niger and the addition of phytase to animal feed has also reduced excretion of phosphate in the manure of pigs and poultry (Maenz, 2001). Phytase sequentially dephosphorylates phytate to yield inorganic phosphate and myo-inositol, which are then absorbed in the small intestine. Phytases are widely distributed in all types of organisms. In plants, phytases rapidly release inorganic phosphate from phytate upon germination. However, plant phytases are not normally produced in sufficient quantities for application on an industrial scale. Phytases have been produced in various plant systems through transgenic approaches, with the aim of reducing production costs as compared to production via microbial fermentation (reviewed in Brinch-Pedersen et al., 2002). Phytase genes have been cloned from Aspergillus species and expressed in transgenic tobacco seeds and leaves (Pen et al., 1993; Verwoerd et al., 1995), in transformed soybean cell-suspension cultures ( $\mathrm{Li}$ et al., 1997), in transgenic soybean and alfalfa (Denbow et al., 1998; Ullah et al., 2002), and in transgenic wheat, rice and canola seeds (Brinch-Pedersen et al., 2000; Zhang et al., 2000; Lucca et al., 2001; Ponstein et al., 2002). The transgenic plant-produced phytase has a lower molecular mass than the fungal enzyme due to differences in glycosylation (Pen et al., 1993; $\mathrm{Li}$ et al., 1997), nevertheless the plant-produced phytase efficiently substitutes for the microbial enzyme in poultry-feeding studies (Pen et al., 1993; Denbow et al., 1998).

Despite the array of potential phytase sources, only soil fungi (A. niger or A. ficuum) are currently used for commercial production of phytase. The phytase produced by the two fungi possesses greater specific activity (100 $\mathrm{U} / \mathrm{mg}$ of protein) (wherein $\mathrm{U}$ is defined as the amount of enzyme that releases $1 \mu \mathrm{mol}$ of phosphorus from phytate per minute) and thermostability compared to other phytases that have been characterized from other microorganisms (Van Gorcom et al., 1995). Both the A. niger or A. ficuum phytase are acid phytases, with a bi-hump $\mathrm{pH}$ optima of 2.5 and 5 , and exhibit little activity above pH 5.5 (Howson and Davis, 1983; Van Gorcom et al., 1995). Consequently, activity is limited to a relatively small region of the monogastric digestive tract, in which the
$\mathrm{pH}$ ranges from 2-3 in the stomach to 4-7 in the small intestine.

Unlike monogastric animals, ruminants (e.g., cattle and sheep) readily utilize the phosphorus in phytate. The rumen is a rich source of microorganisms which produce phytases having biochemical characteristics (such as temperature and $\mathrm{pH}$ stability, low metal ion sensitivity and high specific activity) desirable for industrial applications, such as animal feed supplementation and inositol production (Yanke et al., 1998). Phytase produced by Selenomonas ruminantium has high specific activity $(400 \mathrm{U} / \mathrm{mg})$ when expressed in E. coli, with a bi-hump pH optima of 4.0 and 5.5 and is active between $\mathrm{pH} 3.0$ and 6.0, and a temperature optimum of $60^{\circ} \mathrm{C}$ (Cheng et al., 1999). The phytase gene ( $\operatorname{SrPf6}$ ) was isolated from $S$. ruminantium (Yanke et al., 1998). The appA gene of $E$. coli encodes a bifunctional enzyme exhibiting both acid phosphatase and phytase activities that have identical $\mathrm{pH}$ optima of 4.5, and are active at $\mathrm{pH}$ values from 2.0 to 6.0 (Golovan et al., 2000). The appA enzyme has a specific acid phosphatase activity of $712 \mathrm{U} / \mathrm{mg}$ and phytase activity of $3165 \mathrm{U} / \mathrm{mg}$, and identical temperature optimum of $60^{\circ} \mathrm{C}$ (Golovan et al., 2000). The properties of the phytases encoded by SrPf6 and appA, including the broad low $\mathrm{pH}$ optima, high specific activity, and protease resistance (Cheng et al., 1999; Golovan et al., 2000), make the two enzymes good candidates for industrial production as feed enzyme additives.

There are advantages for using germinated seeds as carriers for phytase. Seeds could be easily transported and distributed for long distances at ambient temperature, have a long shelf life, and subjected to germination at controlled environments within a defined time. During germination, a wide variety of hydrolytic enzymes are activated or synthesized in the endosperm, and these enzymes hydrolyze the reserved starch, protein and lipid stored in seeds, resulting in the production of many essential nutrients for seedling growth (Bewley and Black, 1994). Germination is technologically simple, inexpensive, and easy to carry out on a large scale (Bae and Cheng, 2000). Germinated seeds, rich in highly active enzymes, nutrients, and minerals in easily available form, would be an ideal host system for the production of phytase and useful as a nutritional supplement in animal feeds. Direct application of the germinated seeds in animal feeds may also significantly reduce downstream processing and formulation costs. 
During germination of cereal grains, embryos synthesize gibberellins (GA) that diffuse to aleurone cells and act as signals activating the synthesis and secretion of $\alpha$-amylases and other hydrolases; these enzymes then digest the starch stored in the endosperm and provide sugars for the growth of young seedlings (Jacobsen et al., 1995). The rice $\alpha-$ amylase genes are highly expressed in the endosperm of seeds during germination (Yu et al., 1996), and promoters of two $\alpha$-amylase genes, $\alpha$ Amy $7 / R A m y 1 A$ and $\alpha A m y 8 / R A m y 3 E$, have been shown to direct high levels of foreign gene expression in endosperm of transgenic rice seeds during germination (C.-M. Chiang and S.-M. Yu, unpublished; Itoh et al., 1995).

In the present study, we show that the highly active $S$. ruminantium $(S r P f 6)$ and E. coli (appA) phytases could be expressed in transgenic germinated rice seeds under the control of an $\alpha A m y 8$ promoter. The transgenes were stably inherited and expressed in the progenies. Phytase was expressed in the germinated transgenic rice seeds transiently and in a temporally controlled and tissue-specific manner. We also show that the phytases produced in germinated rice seeds possess high activity over broader $\mathrm{pH}$ optima compared with native phytases and the Aspergillus phytases.

\section{Materials and methods}

\section{Plant material}

The rice variety used in this study was Oryza sativa L. cv. Tainung 67. Immature seeds were dehulled, sterilized with $2.4 \% \mathrm{NaOCl}$ for $1 \mathrm{~h}$, washed extensively with sterile water, and placed on N6D agar medium (Toki, 1997) for callus induction. After 1 month, calli derived from scutella were subcultured on fresh N6D medium for transformation.

\section{Plasmid construction}

The $5^{\prime}$ end of the $S$. ruminantium phytase gene (SrPf6) was modified by PCR using the plasmid pSrPf6 (Cheng et al., 1999) as a DNA template and the forward primer $\left(5^{\prime}\right.$-TTAAGCGATATCGCCAAGGCCC CGGAACAGA-3'), resulting in a recombinant gene in which an EcoRV site (underlined) was incorporated immediately $5^{\prime}$ to the codon (bold) specifying the first amino acid of the mature, processed phytase enzyme. The EcoRV site allows for the fusion of the phytase gene to the signal peptide sequence of the $\alpha$-amylase gene, $\alpha$ Amy 8 . The $3^{\prime}$ end of the phytase gene in pSrPf6 has a $B a m \mathrm{HI}$ site, and therefore, the reverse primer $\left(5^{\prime}-\right.$ ACGCAGGATCCACCTCATAAAACC-3', BamHI site underlined) was used for the PCR. The PCR product was subcloned into the EcoRV and BamHI sites of pBluescript (Strategene) to generate $\mathrm{pBS} / \mathrm{SrPf6}$. The phytase gene appA was cloned by PCR using genomic DNA from ATCC33965 strain E coli (Greiner et al., 1993) as a DNA template. The $5^{\prime}$ primer $\left(5^{\prime}-\mathrm{A}\right.$ CGGCGGATATCCAGAGTGAGCCGGAGCTGA-3', EcoRV site underlined) and $3^{\prime}$ primer (5'-AGGTTG GATCC-TTACAAACTGCACGAAGGGT-3', Bam ${ }^{\prime}$ site underlined) were designed based on the appA gene sequence from E. coli strain K12 (GenBank M58708) (Dassa et al., 1990). The PCR product was subcloned into pBluescript to generate $\mathrm{pBS} / \mathrm{appA}$.

The 500-bp promoter and signal peptide region of $\alpha$ Amy 8 was excised with SalI and HindIII from pAG8 (Chan et al., 1993) and subcloned into pBluescript to generate $\mathrm{pBS} / 8 \mathrm{SP}$. The nopaline synthase gene (Nos) 3'UTRs was PCR-amplified using pBI221 (Clontech) as the DNA template and the oligonucleotide $\left(5^{\prime}-\mathrm{TC}\right.$ CGGATCCCAGATCGTTCAAACATTT-3', BamHI site underlined) as the forward primer and the oligonucleotide (5'-AGCCCGCGGGATCGATCTAGTA ACAT- $3^{\prime}$, SacII site underlined) as the reverse primer. The Nos $3^{\prime} \mathrm{UTR}$ was then subcloned into the BamHI and SacII sites in pBS/8SP to generate pBS/8SPNos. The SrPf6 and appA genes were excised with EcoRV and BamHI from pBS/SrPf6 and pBS/appA, respectively, and subcloned into the same sites in $\mathrm{pBS} / 8 \mathrm{SPN}$ os to generate $\mathrm{pBS} / 8 \mathrm{FN}$ and $\mathrm{pBS} / 8 \mathrm{AN}$. The correct in-frame fusion of the $\alpha A m y 8$ signal peptide sequence with the SrPf6 or appA coding region, and the junction regions, which link the SrPf6 or appA coding region with the Nos $3^{\prime} \mathrm{UTR}$, were all verified by DNA sequencing.

The cauliflower mosaic virus $35 \mathrm{~S}$ RNA (CaMV35S) promoter-hygromycin B phosphotransferase ( $h p h)$ coding sequence-tumor morphology large gene $3^{\prime}$ UTR $(\mathrm{tml})$ fusion gene was excised with EcoRI from pTRA151 (Zheng et al., 1991), subcloned into the EcoRI site of the binary vector pPZP200 (Hajdukiewicz et al., 1994) to generate pPZP/HPH. pPZP/HPH was linearized with SalI and end-blunted and served as a vector. $\mathrm{pBS} / 8 \mathrm{FN}$ and $\mathrm{pBS} / 8 \mathrm{AN}$ were linearized with $P v u \mathrm{II}$ and served as inserts. The insert DNA was respectively ligated with the vector DNA to generate $\mathrm{p} 8 \mathrm{FN}$ and $\mathrm{p} 8 \mathrm{AN}$, respectively. 


\section{Rice transformation}

Plasmids were introduced into Agrobacterium tumefaciens strain EHA101 (Hood et al., 1986) with an electroporator (BTX) according to the manufacturer's instructions. Calli induced from immature rice seeds were co-cultured with Agrobacterium according to the methods described by Hiei et al. (1994) and Toki (1997). Putative transformed calli were selected on hygromycin B. Regenerated transgenic plants were grown and self-pollinated for five generations.

\section{DNA gel blot analysis}

Genomic DNA was isolated from rice leaves as described (Sheu et al., 1996). Genomic DNA (10 $\mu \mathrm{g})$ was digested with EcoRV, fractionated in a $0.7 \%$ agarose gel, and transferred to a nylon membrane (MSI). The membrane was hybridized with ${ }^{32} \mathrm{P}-$ labeled SrPf6 DNA (0.96kb) or appA DNA (1.24kb) as a probe.

\section{RNA gel blot analysis}

Total RNA was isolated from germinated seeds according to Yu et al. (1996). RNA gel blot analysis was performed as described by Thomas (1983). Briefly, $7 \mu \mathrm{g}$ of total RNA was electrophoresed in a $1 \%$ agarose gel containing $10 \mathrm{mM}$ sodium phosphate buffer ( $\mathrm{pH}$ 6.5), transferred to a nylon filter, and hybridized with ${ }^{32} \mathrm{P}$ random primer-labeled SrPf6 DNA $(0.96 \mathrm{~kb})$, appA DNA $(1.24 \mathrm{~kb})$ or rDNA probe. The blot was visualized by autoradiography.

\section{Phytase and $\alpha$-amylase activity assays}

Seeds were imbibed at $28^{\circ} \mathrm{C}$ for $24 \mathrm{~h}$ to synchronize germination, and this time point was defined as day 1. Twenty seeds from each of three individual plants of an independent transgenic line were germinated in the dark at $28^{\circ} \mathrm{C}$ for 5 days. Entire germinated seeds were ground in liquid $\mathrm{N}_{2}$ with a mortar and pestle. Protein extracts for half of the samples were prepared as described (Shimizu, 1992). Briefly, $150 \mu l$ of extracted proteins were incubated with $600 \mu \mathrm{l}$ of $1.5 \mathrm{mM}$ sodium phytate at $37^{\circ} \mathrm{C}$ for $15 \mathrm{~min}$. The reaction was stopped by adding $750 \mu \mathrm{l}$ of $5 \%$ trichloroacetic acid. Following production of phosphomolybdate with $1.5 \mathrm{ml}$ of coloring reagent, the liberated inorganic orthophosphate $(\mathrm{Pi})$ was photometrically measured at $700 \mathrm{~nm}$. The coloring reagent was prepared freshly by mixing four volumes of $1.5 \%$ ammonium molybdate solution in $5.5 \%$ sulfuric acid and one volume of $2.7 \%$ ferrous sulfate solution. One unit of phytase was defined as the amount of enzyme required to liberate $1 \mu \mathrm{mol} \mathrm{Pi}$ from phytate per min per mg total soluble proteins under the assay conditions. Protein extracts from the other half of samples were prepared and $\alpha$-amylase activity determined as described (Yu et al., 1991). For the analysis of tissue-specific expression, 50 dehulled T2 seeds were sterilized, and inoculated on MS liquid medium containing $50 \mathrm{mg} / \mathrm{l}$ of hygromycin for 5 days. The embryos, roots, shoots and endosperms were dissected from the hygromycin resistant germinated seeds and their phytase activity was assayed. Protein concentration of total soluble proteins was determined by the Bio-Rad Coomassie Protein assay kit.

\section{Analysis of optimal pH and temperature conditions for phytase activity}

Transgenic T2 seeds were germinated for 5 days and proteins were extracted. Phytase activity was assayed over a pH range from 1.0 to 9.0. Buffer systems used to cover the $\mathrm{pH}$ range were: $100 \mathrm{mM}$ Gly- $\mathrm{HCl}$ for $\mathrm{pH} 1.0-3.0 ; 100 \mathrm{mM}$ sodium acetate for $\mathrm{pH}$ 3.5-6.0; $100 \mathrm{mM}$ MES for $\mathrm{pH}$ 6.5-7.0; $100 \mathrm{mM}$ Tris- $\mathrm{HCl}$ for pH 8.0-9.0. For analysis of optimal temperatures for phytase activity, proteins in $100 \mathrm{mM}$ sodium acetate, $\mathrm{pH} 5.0$ were analyzed from 20 to $90^{\circ} \mathrm{C}$.

\section{Segregation analysis}

For segregation analysis, 50 seeds of each line of T1 generation were sterilized, and inoculated on MS liquid medium containing $50 \mathrm{mg} / \mathrm{l}$ of hygromycin. Hygromycin resistance/sensitivity was scored after 7 days. For statistic analysis, the $\chi^{2}$-test was performed to analyze the fitness of Mendelian inheritance.

\section{Results}

\section{Expression of phytase in germinated} transgenic rice seeds

Plasmids p8FN and p8AN contain SrPf6 and appA fused downstream of the $\alpha A m y 8$ promoter-signal peptide sequence, respectively. These plasmids were introduced into the rice genome, and the putatively transformed rice calli were selected on medium containing hygromycin. The transformed rice calli 


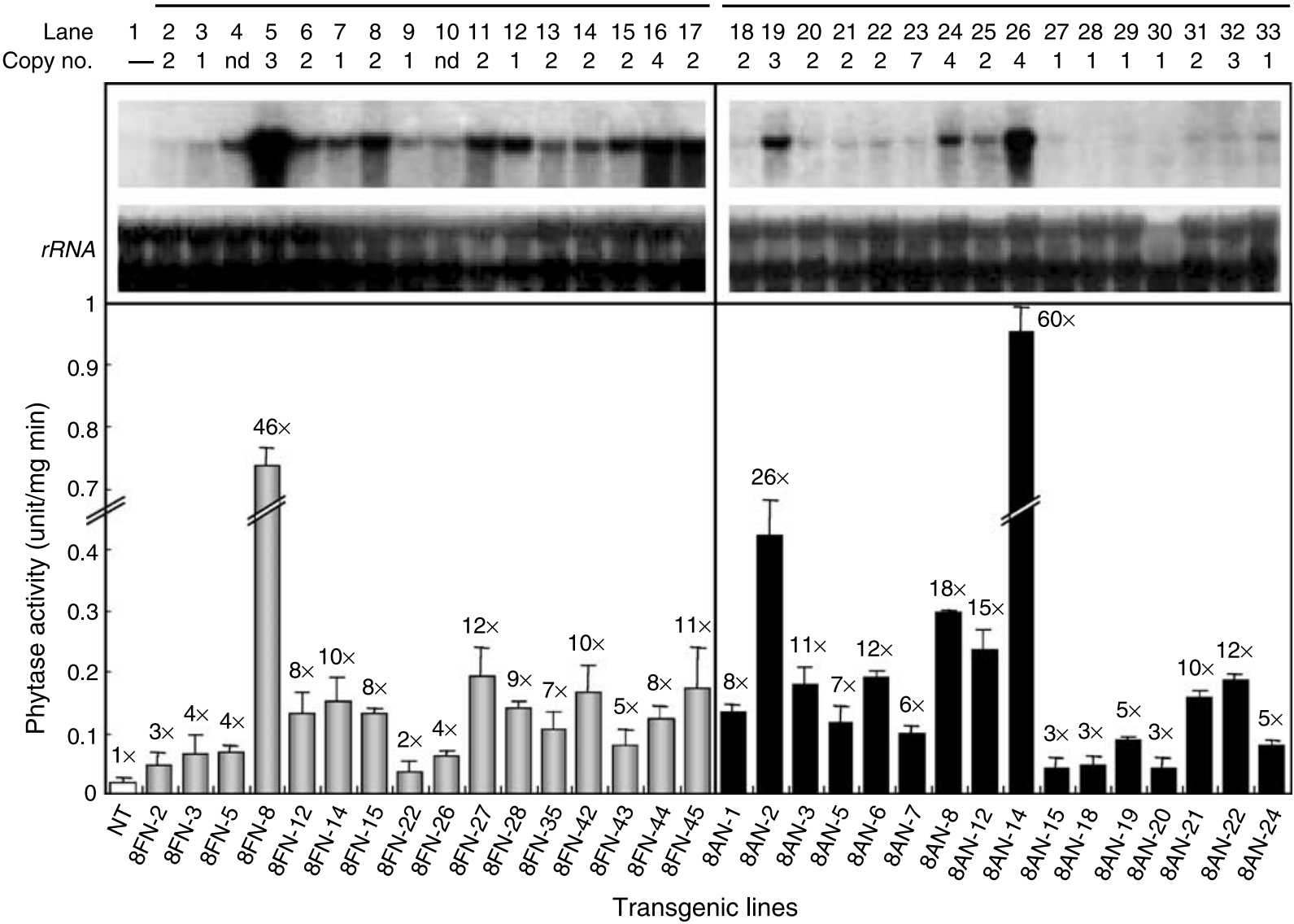

Figure 1. Expression of phytases in germinated transgenic rice seeds. Twenty T1 seeds from each of three individual plants, of each independent transgenic line, were germinated for 5 days. Total RNA was purified from half of germinated seeds and subjected to gel blot analysis using SrPf6 cDNA (left panel), appA cDNA (right panel) or rDNA as a probe. Phytase activities of these transgenic lines were also determined (lower panel). The phytase activity of the non-transformant (NT) was assigned as $1 \times$ and other values were calculated relative to this. Error bars indicate the standard deviation of phytase activity in germinated seeds of three plants. The copy number of the transgenes is indicated above the RNA gel blot and was determined by DNA gel blot analysis (data not shown).

were regenerated, and $\mathrm{T} 1$ seeds of sixteen independent transgenic lines, each containing $\alpha A m y 8-S r P f 6$ (p8FN) or $\alpha A m y 8-a p p A$ (p8AN) chimeric genes, were obtained. The T1 seeds, which could be homozygous or heterozygous for the transgenes were germinated on $50 \mathrm{mg} / \mathrm{l}$ hygromycin for 5 days. Only transgenic seeds germinated and grew under selective conditions and were further analyzed. RNA was extracted from the germinated seeds and subjected to gel blot analysis. The SrPf6 or appA RNA accumulated in germinated transgenic rice seeds, with varying levels among different transgenic lines (Figure 1, upper panel). Total proteins were also extracted from the germinated seeds of these transgenic lines and subjected to phytase activity assays. Phytase activity could be detected in germinated transgenic seeds, with varying levels among different transgenic lines (Figure 1, lower panel). Transgene RNA was not detected in the non-transformed control. However, low levels of endogenous phytase activity were present in the non-transformed seeds. The RNA levels correlated closely with phytase activity, with transgenic lines $8 \mathrm{FN}-8$ and $8 \mathrm{AN}-14$ showing the highest levels of RNA accumulation and phytase activity. The phytase activities in 8FN-8 and 8AN-14 were 46-fold and 60fold, respectively, greater than those present in the non-transformed seeds.

\section{Determination of transgene copy number}

To determine whether the copy number of transgenes affected the expression levels of phytase in transgenic 
(A)

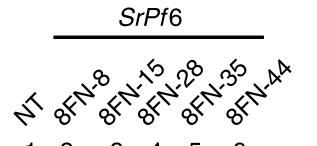

(B)
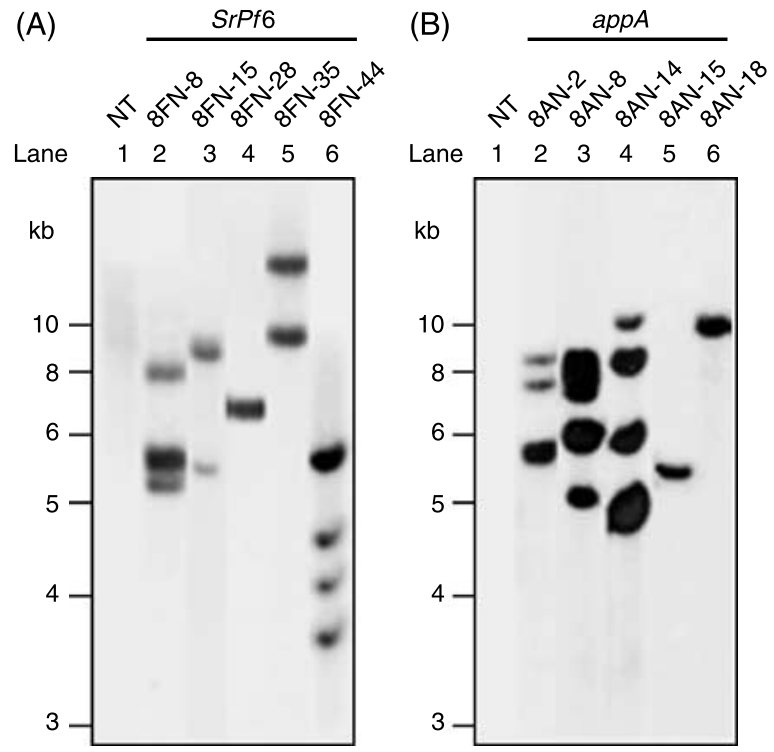

Figure 2. DNA gel blot analysis showing transgene copy numbers. DNA was isolated from transgenic lines expressing SrPf6 or appA, digested with $E c o \mathrm{RV}$, and subjected to gel blot analysis using (A) SrPf6 cDNA or (B) appA cDNA as probes. NT: non-transformant. The molecular weight markers are shown on the left of the autoradiogram.

seeds, genomic DNA was extracted from T1 transgenic plants, digested with EcoRV, and subjected to DNA gel blot analysis. The transgene copy number was in the range of 1 to 4 . Lines $8 \mathrm{FN}-8$ and $8 \mathrm{AN}$ 14, which had the highest RNA levels and phytase activities (Figure 1), contained three and four transgene copies, respectively (Figure 2(A), lane 2 and Figure 2(B), lane 4). Line 8AN-2, which contained three copies of the transgene (Figure 2(B), lane 2), also had a relatively high phytase activity (Figure 1). The results suggest that a high copy number of the transgene might contribute to a higher level of phytase activity. However, the transgene copy number does not necessarily correlate with phytase expression level, as both lines 8FN-44 (Figure 2(A), lane 6) and $8 \mathrm{AN}-8$ (Figure 2(B), lane 3) contained four

Figure 3. Temporal expression of phytase in transgenic rice seeds during germination. Twenty $\mathrm{T} 2$ seeds, each from two transgenic lines expressing (A) SrPf6 phytase or (B) appA phytase, were germinated for various lengths of time and phytase and $\alpha$-amylase activities were determined. Twenty T2 seeds each of three non-transgenic lines were used to measure the $\alpha$-amylase activity. Each data point is the average of three replicates. Patterns of the $\alpha$-amylase activities in the three non-transgenic lines were similar. Therefore, data of only one representative line showing $\alpha$-amylase activity is presented. NT: non-transformant. copies of the transgenes but had significantly lower level of phytase activity compared to lines $8 \mathrm{FN}-8$ and 8AN-14 (Figure 1).
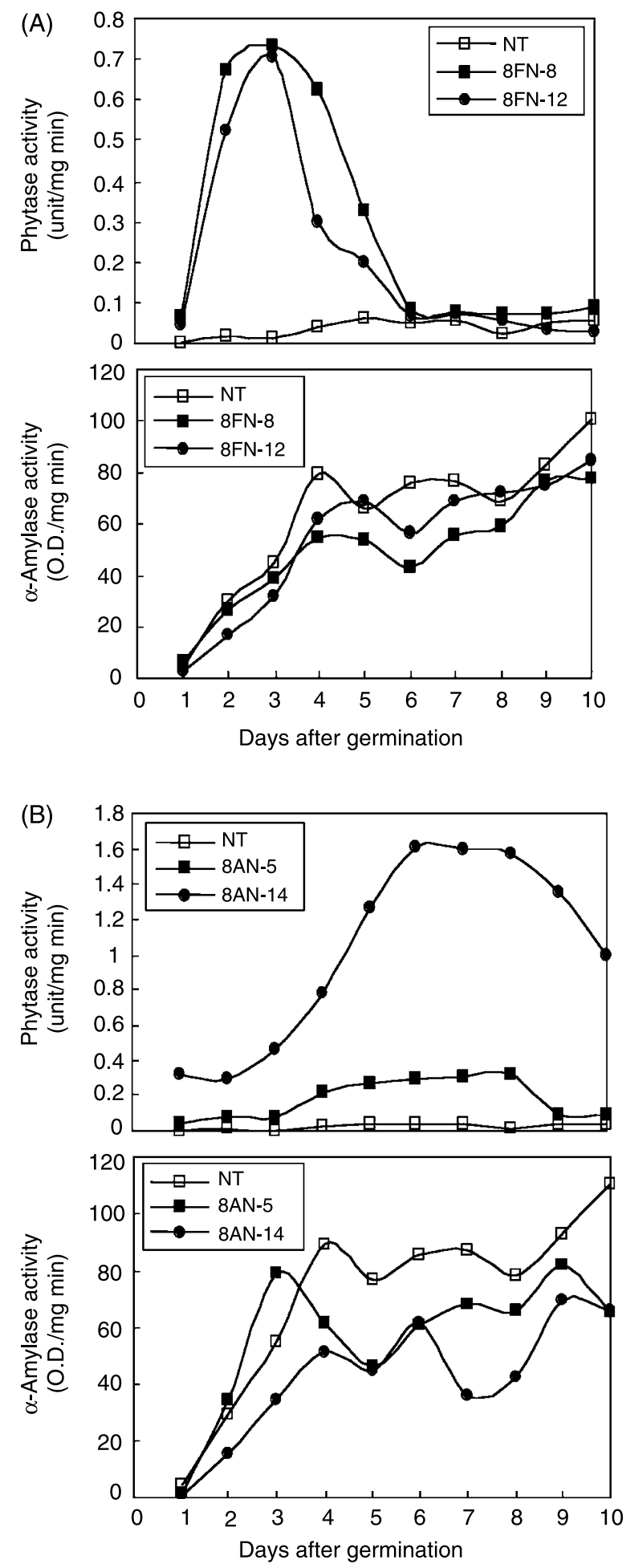
Temporal and tissue-specific expression of phytase in germinating seeds

To determine the temporal expression pattern of phytase in germinated seeds, T2 seeds were germinated for various lengths of time and phytase activities determined. The phytase activity in germinating seeds of lines expressing SrPf6 phytase increased rapidly, peaked on day 3 and then declined rapidly to basal level on day 6 (Figure 3(A), upper panel); while in lines expressing appA phytase activity increased gradually, peaked between days 6 and 8 after germination and declined afterward (Figure 3(B), upper panel). Endogenous phytase activity was also detectable in non-transformed seeds, but remained at a low level throughout the entire germination period.

To determine whether phytases expressed under the control of $\alpha A m y 8$ promoter showed similar expression patterns as the endogenous $\alpha$-amylases, $\alpha$ amylase activities in the germinating seeds of the two
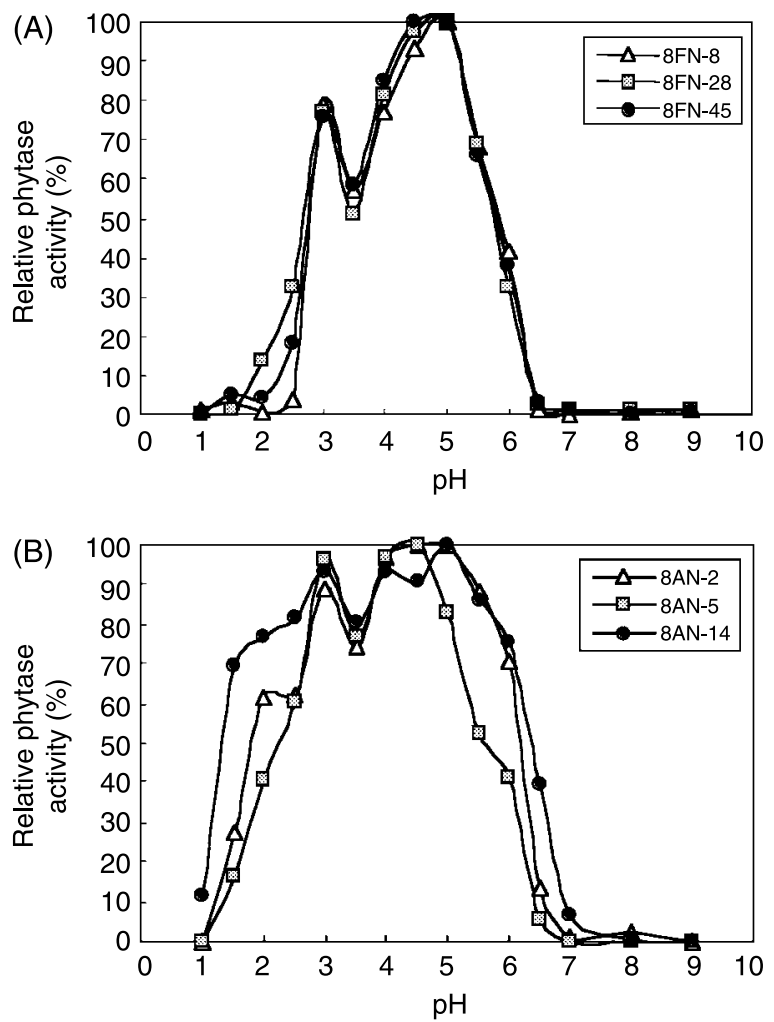

Figure 4. $\mathrm{pH}$ profile of phytase activity expressed in germinated transgenic rice seeds. Twenty T2 seeds, each from three transgenic rice lines expressing (A) SrPf6 phytase or (B) appA phytase, were germinated for 5 days. Phytase activity in whole germinated seeds was determined over a $\mathrm{pH}$ range of 1-9. transgenic lines were also determined. The $\alpha$-amylase activity in all transgenic lines increased with time in a fluctuating manner during germination (Figure 4(A) and (B), lower panels), which was consistent with our previous observations (Yu et al., 1996). These results indicate that the recombinant phytase expression in germinated transgenic rice seeds is transient and does not follow the pattern of $\alpha$-amylase expression.

To determine the tissue-specific expression pattern of phytase in germinating transgenic rice seeds, $\mathrm{T} 2$ seeds were germinated for 5 days. Embryos, roots, shoots and endosperms were dissected from the germinating seeds and their phytase activity assayed. Levels of SrPf6 and appA phytase were highest in endosperm tissues, followed by embryos for all transgenic lines; very low phytase activity was detected in roots and shoots (data not shown).
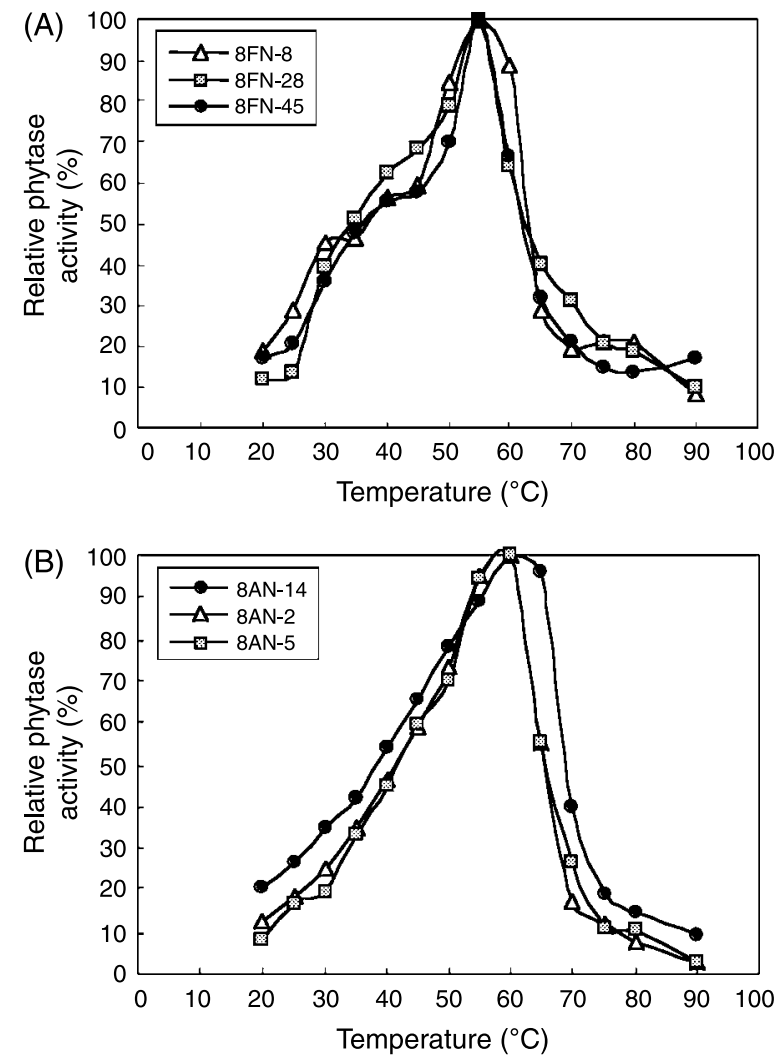

Figure 5. Temperature profile of phytase activity expressed in germinated transgenic rice seeds. T2 seeds of transgenic rice lines expressing (A) SrPf6 or (B) appA were germinated for 5 days. Phytase activity in whole germinated seeds was determined at temperatures between 20 and $90^{\circ} \mathrm{C}$. 
pH and temperature optima for phytase activity

Stable and active phytase in an acidic environment is essential for the hydrolysis of phytate in the animal gastrointestinal track. To determine the optimal $\mathrm{pH}$ for phytase activity in germinated transgenic rice seeds, T2 seeds were germinated for 5 days. The optimal $\mathrm{pH}$ for SrPf6 phytase activity in three transgenic lines was similar, with activity peaking at $\mathrm{pH} 3.0$ and $\mathrm{pH} 4.5-5.0$ and approximately 70 and $40 \%$ activity remained at pH 5.5 and 6.0, respectively (Figure 4(A)). The optimal $\mathrm{pH}$ for appA phytase in three transgenic lines was also similar, with activity peaking at $\mathrm{pH} 3.0$ and $\mathrm{pH} 4.0-5.0$ and $40-75 \%$ activity remained at $\mathrm{pH}$ 2.0 and $\mathrm{pH} 6.0$ (Figure 4(B)).

Phytase active at high temperature may facilitate feed processing. To determine the optimal temperature for phytase activity in germinated transgenic rice seeds, T2 seeds were germinated for 5 days. The optimal temperature for phytase activity present in three transgenic lines, each expressing $\operatorname{SrPf6}$ or appA phytases, were 55 and $60^{\circ} \mathrm{C}$, respectively (Figure 5(A) and $(\mathrm{B}))$.

\section{Stable inheritance and expression of phytase} genes in progenies of transgenic rice

Germinated seeds of transgenic line $8 \mathrm{AN}-14$ contained four copies of the appA transgene and expressed the highest level of phytase. To determine whether the transgenes in this line were stably inherited and expressed in progenies, genomic DNA of T0, T1, T2, T3 and T4 plants was extracted and subjected to DNA gel blot analysis. Four transgene insertion sites were observed in the genomes of transgenic line $8 \mathrm{AN}-14$ over five generations (Figure 6(A)). There could be a few tandem repeats of T-DNA in one insertion site within a DNA fragment of $6 \mathrm{~kb}$, as it showed a higher intensity signal than the other fragments on the gel blot. Segregation analysis showed a Mendelian segregation (3:1 ratio) (data not shown), suggesting that the appA gene was integrated in one locus. Meanwhile, similar phytase activity between T1, T2, T3 and T4 germinated seeds of this line was observed throughout four generations (Figure 6(B)). These results indicate that the transgenes in line 8AN-14 were stably integrated and no recombination had occurred, and were expressed in germinated seeds at similar levels for at least four generations.

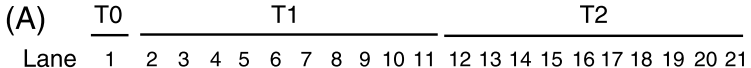
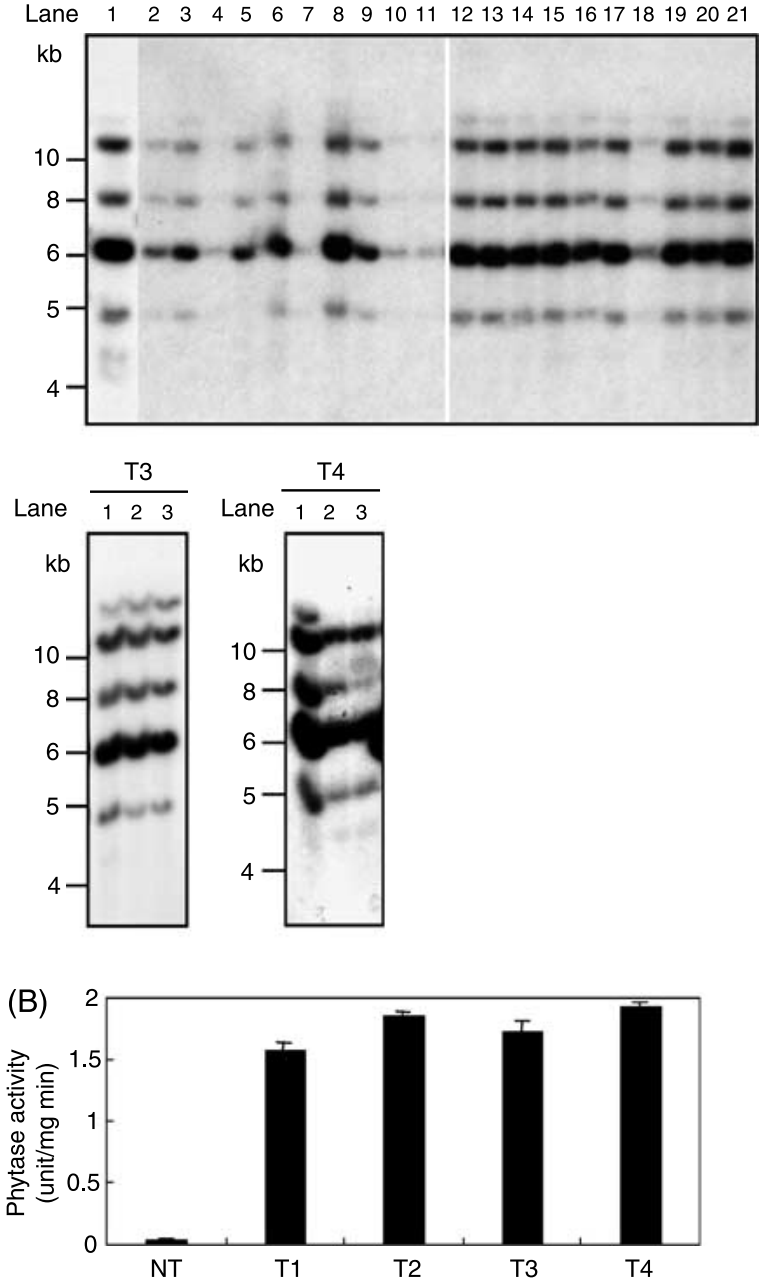

Figure 6. Transgene copy number and phytase activity assays over different generations. (A) DNA was extracted from leaves of 8AN-14 seedlings over five generations (T0-T4), digested with $E c o \mathrm{RV}$, and subjected to gel blot analysis using appA cDNA as a probe. (B) Twenty seeds from each of three individual plants, belonging to four generations (T1-T4), were germinated for 5 days and phytase activity determined. NT: non-transformant. Error bars indicate the standard deviation of phytase activity in germinated seeds from three plants.

\section{Discussion}

To date, phytase genes expressed in transgenic plants have been limited to those derived from soil fungi A. niger or A. ficuum. In the present study, we demonstrated for the first time that two bacterial phytase genes could be produced in germinated transgenic rice seeds at high levels, with high enzymatic activity. The bacterial phytases have broader $\mathrm{pH}$ optima and higher specific activities as compared to the fungal 
enzymes (Cheng et al., 1999; Golovan et al., 2000). The introduced genes were stably integrated into the rice genome and were inherited by progenies. Among 16 transgenic lines, each expressing ruminal bacterial (SrPf6) phytase or E. coli (appA) phytase, lines 8FN-8 and $8 \mathrm{AN}-14$ expressed the highest levels of phytases in germinated rice seeds. Lines $8 \mathrm{FN}-8$ and $8 \mathrm{AN}-14$ contain three and four copies of the transgenes, respectively, which is relatively high compare to other transgenic lines. However, some transgenic lines that contained similar high numbers of transgene had low phytase activity. This suggests that multiple copies of transgenes could, but may not necessarily, contribute to higher expression levels of phytase in germinated rice seeds.

In the present study, the 500-bp long $\alpha A m y 8$ promoter was sufficient for directing tissue-specific expression of phytases in germinating transgenic rice seeds. The tissue-specific expression patterns of phytases were consistent with our previous observations that the rice $\alpha A m y 8$ promoter is most active in endosperm, followed by embryos, and is least active in the roots and shoots of germinated transgenic rice seeds (Chen et al., 2002). It is interesting to note that the temporal expression patterns of the two bacterial phytases are different from each other as well as being different from that of the endogenous $\alpha$ amylases in germinating rice seeds. The accumulation of the appA, but not the SrPf6, phytase follows the kinetics of accumulation of total extractable seed proteins that were used as reference for phytase activity (U/min/mg) (data not shown). A possible explanation for the difference in expression patterns between the introduced phytases and the endogenous $\alpha$-amylase is that additional regulatory sequences responsible for the fluctuating expression patterns of $\alpha$-amylases is not present in the 500-bp long $\alpha A m y 8$ promoter. The difference in expression patterns between the two introduced phytases could be due to their different biochemical properties, protein stability or interaction with other factors, which affects their ability to accumulate in germinating seeds.

Another phenomenon noted in this study was that the endogenous $\alpha$-amylase activity in nontransformants was higher than that in transgenic seeds. We have found that transgenic seeds germinated at a slightly slower rate than the non-transformants. Transgenic line $8 \mathrm{AN}-14$ had the highest phytase activity but the lowest endogenous $\alpha$-amylase activity (Figure 3(B)), also had the slowest germination rate compared with the non-transformants and other lines with lower phytase activity. $\alpha$-Amylase activity has been shown to correlate with rice seedling vigor, and that is essential for rapid germination and early seedling growth (Williams and Peterson, 1973; Lee et al., 1986; Sasahara et al., 1986). One possible explanation for the reduced $\alpha$-amylase activity could be competition between the endogenous and introduced $\alpha$ amylase gene $(\alpha A m y 8)$ promoters for transcription factors. However, although this line has a lower germination rate, normal seedling growth of $8 \mathrm{AN}-14$ resumed 3 weeks after germination, and the yield was normal compared with the non-transformants. The transient expression of phytase in germinating seeds, without adverse effect on plant development and paying a yield penalty, could be a beneficial feature for using germinated cereal grains as a phytase carrier.

The optimal $\mathrm{pH}$ for phytase activity in germinated rice seeds shifted from a bi-hump pH optima of 4.0 and 5.5 (Cheng et al., 1999) to a bi-hump peak of 3.0 and 4.0-5.0 for SrPf6 phytase, and from an original single peak of 4.5 (Golovan et al., 2000) to a bi-hump peak of 3.0 and 4.0-5.0 for the appA phytase. One possible explanation for the high activity at broader $\mathrm{pH}$ ranges could be due to structural changes in the two bacterial phytases expressed in germinated transgenic rice seeds. The fungal phyA phytase expressed in alfalfa has a shifted $\mathrm{pH}$ optima for maximal enzyme activity compared with the native phytase, and a difference in enzyme glycosylation has been proposed to alter the pH optima (Ullah et al., 2002). There are three and one potential glycosylation sites in the appA and SrPf6 phytases, respectively. Whether the two phytases are glycosylated remains to be determined.

Expression of the A. ficuum phytase in transgenic tobacco leaves showed a bi-hump pH optima peaking at $\mathrm{pH} 4.0$ and 2.0, as opposed to $\mathrm{pH} 5.0-5.5$ and 2.5 for the native fungal phytase, and became inactive at $\mathrm{pH}$ 2.5-3.0 (Ullah et al., 1999). Expression of the same phytase in transgenic alfalfa showed a bi-hump pH optima peaking at $\mathrm{pH} 5.0$ and 3.0 (Ullah et al., 2002). In both cases, the narrowed optimal $\mathrm{pH}$ ranges may limit the function of phytase in the animal gastrointestinal tracts. In the present study, by contrast, we showed that the SrPf6 and appA phytases possess high activities at broadened $\mathrm{pH}$ ranges over 3.0-5.5 and 2.0-6.0, respectively (Figure 6). The broad and acidic optimal $\mathrm{pH}$ profiles of the two phytases expressed in germinated rice seeds would allow them to function well in the stomach and small intestine of animals and are essential features for any potential use as feed additives. The temperature optima profiles of the SrPf6 
and appA phytases expressed in germinated rice seeds remained the same as the native form phytases, indicating that the shift of $\mathrm{pH}$ optima is independent of the thermo-tolerance of the two enzymes.

Although appA is inserted at four different sites in the genomes of transgenic line $8 \mathrm{AN}-14$, the transgenes are stably inherited and phytase activity in the germinated seeds is stable over four generations. This suggests that no gene segregation or gene silencing has occurred in this line. The A. fumigatus phytase expressed in transgenic rice increased phytase level 130 -fold as compared with the endogenous phytase level in rice grains (Lucca et al., 2001). We found that the endogenous phytase activity present in rice grains is lower than that determined at day 1 after germination (Figure 3(A) and (B), upper panels). The yields of $\operatorname{SrPf6}$ and appA phytase in germinated transgenic rice seeds are estimated as 0.5 and $0.1 \%$ of total soluble proteins, respectively. Although the protein yields are not high, phytase activities in germinated T3 seeds of lines $8 \mathrm{AN}-14$ and $8 \mathrm{FN}-8$ are 6000 and $2500 \mathrm{U} / \mathrm{kg}$ dry mass, respectively, which are similar to that reported for transgenic wheat (3000 U/kg mass) (Brinch-Pedersen et al., 2000). Chickens were used to compare the efficacy of providing dietary phytase either as a commercial supplement or as a recombinant protein in germinated transgenic rice seeds. Our preliminary result shows that supplement in feeds of chickens with germinated transgenic rice seeds, at much reduced units per $\mathrm{kg}$ of feed, has resulted in growth rates comparable to the growth rates of chickens fed with a standard meal supplemented with a commercial microbial derived phytase (S.-M. Yu, unpublished result). Recently, we expressed the appA phytase under the control of another modified $\alpha$-amylase gene promoter, and phytase activity up to $50,000 \mathrm{U} / \mathrm{kg}$ in germinated seeds was obtained (S.-M. Yu, unpublished). The potential use of these transgenic seeds as additives for improving digestability of phytic acid in animal feeds and reduction of phosphate excretion in the animal manure is currently being analyzed.

In summary, in the present study, we have demonstrated three unique features of expressing two bacterial phytases in germinated transgenic rice seeds: (1) transient expression without paying a yield penalty; (2) high activity over broad pH ranges; (3) germinated seeds provide extra hydrolytic enzymes and nutrition. These features make the germinated cereal grains an idea system for expressing high activity phytase in animal feeds.

\section{Acknowledgement}

We thank Dr Tuan-hua David Ho for critical review of the manuscript and Ms Lin-Tze Yu for technical assistance. This work was supported by grants from Academia Sinica, the National Science Council (NSC87-2611-B-001-004-B30, NSC88-2311-B-001028-B30, NSC89-2311-B001-050-B29), and the Biomedical Research Foundation of the Republic of China.

\section{References}

Austin S, Bingham ET, Koegel RG, Mathews DE, Shahan MN and Straub RJ (1994) An overview of a feasibility study for the production of industrial enzymes in transgenic alfalfa. In: Bajpai RK and Prokop A (eds), Recombinant DNA Technology II. (pp. 234-244) New York Academy of Sciences, New York.

Bae HD and Cheng KJ (2000) Production of enzyme products and raw feed materials using grain seeds. US Patent No. 6,063,431.

Bewley JD and Black M (1994) Mobilization of stored seeds reserves. In: Bewley JD and Black M (eds), Seeds Physiology of Development and Germination. Chapter 7 (pp. 293-343) Plenum Press, New York.

Brinch-Pedersen H, Olesen A, Rasmussen SK and Holm PB (2000) Generation of transgenic wheat (Tritivum aestivum L.) for constitutive accumulation of an Aspergillus phytase. Mol Breeding 6: 195-206.

Brinch-Pedersen H, Sorensen LD and Holm PB (2002) Engineering crop plants: getting a handle on phosphate. Trends Plant Sci 7: $118-125$.

Chan MT, Chang HH, Ho SL, Tong WF and Yu SM (1993) Agrobacterium-mediated production of transgenic rice plants expressing a chimeric $\alpha$-amylase promoter $/ \beta$-glucuronidase gene. Plant Mol Biol 22: 491-506.

Chen PW, Lu CA, Yu TS, Tseng TH, Wang CS and Yu SM (2002) Rice $\alpha$-amylase transcriptional enhancers direct multiple mode regulation of promoters in transgenic rice. J Biol Chem 277: 13641-13649.

Cheng KJ, Sellnger LB, Yanke LJ, Bae HD, Zhou L and Forsberg CW (1999) Phytases of ruminal microorganisms. US Patent No. 5,939,303.

Dassa J, Marck C and Boquet PL (1990) The complete nucleotide sequence of the Escherichia coli gene appA reveals significant homology between $\mathrm{pH} 2.5$ acid phosphatase and glucose-1phosphatase. J Bacteriol 172: 5497-5500.

Denbow DM, Grabau EA, Lacy GH, Kornegay ET, Russell DR and Umbeck PF (1998) Soybeans transformed with a fungal phytase gene improve phosphorus availability for broilers. Poult Sci 77: 878-881.

Golovan S, Wang G, Zhang J and Forsberg CW (2000) Characterization and overproduction of the Escherichia coli appA encoded bifunctional enzyme that exhibits both phytase and acid phosphatase activities. Can J Microbiol 46: 59-71.

Greiner R, Konietzny U and Jany K (1993) Purification and characterization of two phytases from Escherichia coli. Arch Biochem Biophys 303: 107-113.

Hajdukiewicz P, Svab Z and Maliga P (1994) The small, versatile pPZP family of Agrobacterium binary vectors for plant transformation. Plant Mol Biol 25: 989-994. 
Hiei Y, Ohta S, Komari T and Kumashiro T (1994) Efficient transformation of rice (Oryza sativa L.) mediated by Agrobacterium and sequence analysis of the boundaries of the T-DNA. Plant $J$ 6: $271-282$.

Hood EE, Helmer GL, Fraley RT and Chilton MD (1986) The hypervirulence of Agrobacterium tumefaciens A281 is encoded in a region of pTiBo542 outside of T-DNA. J Bacteriol 168: 1291-1301.

Howson SJ and Davis RP (1983) Production of phytatehydrolysing enzyme by some fungi. Enzyme Microb Technol 5: 377-382.

Itoh K, Yamaguchi J, Huang N, Rodriguez RL, Akazawa T and Shimamoto K (1995) Developmental and hormonal regulation of rice $\alpha$-amylase (RAmy1A)-gusA fusion genes in transgenic rice seeds. Plant Physiol 107: 25-31.

Jacobsen JV, Gubler F and Chandler PM (1995) Gibberellin action in germinated cereal grains. In: Davies PJ (ed) Plant Hormones: Physiology, Biochemistry, and Molecular Biology. (pp. 246-271) Kluwer Academic Publishers, Dordrecht

Lee CC, Li CC and Sung FJM (1986) Physiological and genetic studies on seedling vigor in rice (Oryza sativa L.). II. Inheritances of $\alpha$-amylase activity and seedling vigor in rice. J Agric Assoc China 135: 17-24.

Li J, Hegeman CE, Hanlon RW, Lacy GH, Denbow MD and Grabau EA (1997) Secretion of active recombinant phytase from soybean cell-suspension cultures. Plant Physiol 114: 1103-1111.

Lucca P, Hurrell R and Potrykus I (2001) Genetic engineering approaches to improve the bioavailability and the level of iron in rice grains. Theor Appl Genet 102: 392-397.

Maenz DD (2001) Enzymatic characterisation of phytases as they relate to their use in animal feeds. In: Bedford MR and Partridge GG (eds), Enzymes in Farm Animal Nutrition. (pp. 61-84) CAB International, Walling ford, UK.

Pen J, Verwoerd TC, van Paridin PA, Beukeder RF, van der Elzen PJM, Geerse K et al. (1993) Phytase-containing transgenic seed as a novel feed additive for improved phosphorus utilization. Bio/Technol 11: 811-814.

Ponstein AS, Bade JB, Verwoerd TC, Molendijk L, Storms J, Beudeker RF et al. (2002) Stable expression of Phytase (phyA) in canola (Brassica napus) seeds: towards a commercial product. Mol Breeding 10: 31-44.

Ravindran V, Bryden WL and Kornegay ET (1995) Phytates : occurrence, bioavailability and implications in poultry nutrition. Poult Avain Bio Rev 6: 125-143.

Sasahara T, Ikarashi H and Kambayashi M (1986) Genetic variations in embryo and endosperm weight, seedling growth parameters and $\alpha$-amylase activity of the germinated grains in rice (Oryza sativa L.). Jpn J Breed 36: 248-261.
Sheu JJ, Yu TS, Tong WF and Yu SM (1996) Carbohydrate starvation stimulates differential expression of rice $\alpha$-amylase genes that is modulated through complicated transcriptional and posttranscriptional processes. J Biol Chem 271: 26998-27004.

Shimizu M (1992) Purification and characterization of phytase from Bacillus subtilis (natto) N-77. Biosci Biotechnol Biochem 56: 1266-1269.

Thomas PS (1983) Hybridization of denatured RNA transferred or dotted nitrocellulose paper. Meth Enzymol 100: 255-266.

Toki S (1997) Rapid and efficient Agrobacterium-mediated transformation in rice. Plant Mol Biol Rep 15: 16-21.

Ullah AH, Sethumadhavan K, Mullaney EJ, Ziegelhoffer T and Austin-Phillips S (1999) Characterization of recombinant fungal phytase (phyA) expressed in tobacco leaves. Biochem Biophys Res Commun 264: 201-206.

Ullah AH, Sethumadhavan K, Mullaney EJ, Ziegelhoffer T and Austin-Phillips S (2002) Cloned and expressed fungal phyA gene in alfalfa produces a stable phytase. Biochem Biophys Res Commun 290: 1343-1348.

Van Gorcom RFM, van Hartingsveldt W, van Paridon PA, Veenstra AE, Luiten RGM and Selten GCM (1995) Cloning and expression of phytase from Aspergillus. US Patent No. $5,436,156$.

Verwoerd TC, van Paridon PA, van Ooyen AJ, van Lent JW, Hoekema A and Pen J (1995) Stable accumulation of Aspergillus niger phytase in transgenic tobacco leaves. Plant Physiol 109: 1199-1205.

Williams JF and Peterson ML (1973) Relations between $\alpha$ amylase activity and growth of rice seedlings. Crop Sci 13: 612-615.

Yanke LJ, Bae HD, Selinger LB and Cheng KJ (1998) Phytase activity of anaerobic ruminal bacteria. Microbiology 144: 1565-1573.

Yu SM, Kuo YH, Sheu G, Sheu YJ and Liu LF (1991) Metabolic derepression of $\alpha$-amylase gene expression in suspensioncultured cells of rice. J Biol Chem 266: 21131-21137.

Yu SM, Lee YC, Fang SC, Chan MT, Hwa SF and Liu LF (1996) Sugars act as signal molecules and osmotica to regulate the expression of $\alpha$-amylase genes and metabolic activities in germinating cereal grains. Plant Mol Biol 30: 1277-1289.

Zhang ZB, Kornegay ET, Radcliffe JS, Wilson JH and Veit HP (2000) Comparison of phytase from genetically engineered $A s$ pergillus and canola in weanling pig diets. J Anim Sci 78: 2868-2878.

Zheng Z, Hayashomoto A, Li Z and Murai N (1991) Hygromycin resistance gene cassettes for vector construction and selection of transformed rice protoplasts. Plant Physiol 97: 832-835. 